\title{
Schistosoma mansoni: a method for inducing resistance to praziquantel using infected Biomphalaria glabrata snails
}

\author{
Flávia FB Couto', Paulo Marcos Z Coelho'/+, Neusa Araújo', John R Kusel², \\ Naftale Katz ${ }^{1}$, Liana K Jannotti-Passos ${ }^{3}$, Ana Carolina A Mattos ${ }^{1}$ \\ ${ }^{1}$ Laboratório de Esquistossomose ${ }^{3}$ Moluscário Lobato Paraense, Instituto de Pesquisas René Rachou-Fiocruz, Belo Horizonte, MG, Brasil \\ ${ }^{2}$ Division of Infection and Immunity, Faculty of Biomedical and Life Sciences, University of Glasgow, Scotland, UK
}

To elucidate the mechanisms of antischistosoma resistance, drug-resistant Schistosoma mansoni laboratory isolates are essential. We developed a new method for inducing resistance to praziquantel (PZQ) using successive drug treatments of Biomphalaria glabrata snails infected with $\mathrm{S}$. mansoni. Infected $\mathrm{B}$. glabrata were treated three times with $100 \mathrm{mg} / \mathrm{kg} P Z Q$ for five consecutive days with a one-week interval between them. After the treatment, the cercariae (LE-PZQ) produced from these snails and the LE strains (susceptible) were used to infect mice. Forty-five days after infection, mice were treated with $200,400 \mathrm{or} 800 \mathrm{mg} / \mathrm{kg} P Z Q$. Thirty days post-treatment, we observed that the mean number of worms recovered by perfusion was significantly higher in the group of mice infected with the $L E-P Z Q$ isolate treated with 200 and $400 \mathrm{mg} / \mathrm{kg}$ in comparison to the LE strain with the same treatment. Moreover, there was a significant difference between the $E D_{50}$ (effective dose required to kill $50 \%$ of the worms) of the LE-PZQ isolate (362 mg/kg) and the LE strain $(68 \mathrm{mg} / \mathrm{kg}$ ). In the in vitro assays, the worms of the LE-PZQ isolate were also less susceptible to PZQ. Thus, the use of infected snails as an experimental model for development of resistance to S. mansoni is effective, fast, simple and cheap.

Key words: Schistosoma mansoni - Biomphalaria glabrata - praziquantel - resistance induction - new method

The current strategy for schistosomiasis control is based on large-scale treatments of populations aimed at reducing disease morbidity (WHO 2002). Currently, praziquantel (PZQ) is the drug of choice (Utzinger \& Keiser 2004, Fenwick \& Webster 2006), with the main advantages of its use being oral administration, single dose, low toxicity and low cost (Fenwick et al. 2003, Utzinger $\&$ Keiser 2004). Despite the advantages of PZQ, there is concern about the development of Schistosoma mansoni resistance to PZQ, both under laboratory and field conditions (Abdul-Ghani et al. 2009). In the laboratory, induction of resistance is based on the treatment of mice infected with $S$. mansoni, initially using sub-curative doses of PZQ. Afterwards, the dosage is increased for at least seven passages in mice/snails to complete the life cycle of the parasite (Ismail et al. 1994, Fallon et al. 1995).

The complete mechanism of action of PZQ is still unclear (Doenhoff et al. 2008). Obtaining resistant strains is important for the evaluation of such mechanisms as well as for the development of alternative drugs for schistosomiasis treatment and control. Studies show that PZQ is effective not only in adult worms, but also in the intramolluscan phase of the parasite (Coelho et al. 1988, Mattos et al. 2006, 2007). We report a novel meth-

Financial support: CNPq, CAPES

+ Corresponding author: coelhopm@cpqrr.fiocruz.br

Received 9 August 2010

Accepted 12 November 2010 od for the induction (or selection) of $S$. mansoni worms resistant to PZQ using successive treatments of infected Biomphalaria glabrata snails.

\section{SUBJECTS, MATERIALS AND METHODS}

Parasites and hosts - The $S$. mansoni (LE strain) life cycle was maintained using B. glabrata (Barreiro de Cima strain) snails as intermediate hosts and Swiss mice as definitive hosts, according to Pellegrino and Katz (1968) and Souza et al. (1995).

Perfusion of adult worms from infected mice - Two methods were used. The methodology described by Pellegrino and Siqueira (1956) used a needle attached to a Brewer's automatic pipetter to inject saline solution under pressure into the descendent aorta. Afterwards, saline was injected into the hepatic hilum of mice after sectioning the portal vein, allowing the perfusion of the portal system and mesenteric veins. Worms were recovered and counted. To recover the worms using the methodology described by Smithers and Terry (1965) the portal vein of the mice was sectioned and the culture medium was gently injected into the base of the left ventricle of the infected mice's hearts. It is not possible to recover all the worms using this methodology with a lower pressure injection, but the integrity of the parasite's tegument is preserved. Therefore, this methodology is ideal for the recovery of worms when the goal is to cultivate or evaluate other parameters such as tegumental integrity and/or excretory activity.

Induction of resistance to $P Z Q$ in the intramolluscan phase - Two-hundred B. glabrata were individually infected with 10 S. mansoni miracidia (Mattos et al. 2007). Thirty days post-infection the snails were exposed to ar- 
tificial light for $1 \mathrm{~h}$ to verify the shedding of cercariae (Souza et al. 1995). The snails shedding cercariae were divided into two groups (infected snail or infected snails treated with PZQ). The snails were individually weighed using an analytical balance and the snails' mean weight was used to calculate the drug dosage to be administered. The snails were individually treated with $100 \mathrm{mg} /$ $\mathrm{kg}$ PZQ for five consecutive days. This treatment was repeated three times, with a one-week interval between the treatments. PZQ was added to the $100 \mathrm{mg}$ of food (mouse chow; Nuvital) daily allowance. The ration was reconstituted in water until it became pasty and then PZQ was added. The untreated snails received the same amount of food daily without PZQ (Mattos et al. 2007). The daily amount of food given each day was totally ingested by each snail, suggesting that the snails received all of the drugs offered in ration. The snails were kept in plastic glasses containing $200 \mathrm{~mL}$ dechlorinated water which was changed daily. At the end of the treatments, the snails were exposed each week to artificial light until cercarial shedding occurred in sufficient number for the infection of mice, which occurred in about 60 days.

Evaluation of $P Z Q$ pressure on parasites at the intramolluscan phase - Treatment with PZQ: mice were infected with $25 S$. mansoni cercariae by the subcutaneous route (Pellegrino \& Katz 1968). Eighty-four mice were infected with cercariae derived from snails treated with PZQ, called the LE-PZQ isolate and another 84 mice infected with cercariae developed from untreated snails, called the LE strain. Forty-five days after infection, mice were divided into groups (12 mice in each group). Two experiments were performed: in the first the mice were treated with 200 or $400 \mathrm{mg} / \mathrm{kg}$ PZQ; in the second experiment, mice were treated with 200,400 or $800 \mathrm{mg} / \mathrm{kg}$. In both experiments a single oral dose was used. An untreated group was included as a control. Thirty-three days after treatment, mice were submitted to perfusion for evaluation of worm burden reduction (Pellegrino \& Siqueira 1956). The percentage of reduction for each group and each experiment was calculated according to the following formula:

$$
\% \text { reduction }=\frac{\text { (mean of worms in control group - mean of worms in }}{\text { control treated) }} \times 100
$$

The mean of worm reduction related to the experiments 1 and 2 for each PZQ dose was calculated and then the effective dose required to kill $50 \%$ of the worms $\left(\mathrm{ED}_{50}\right)$ was estimated. Data were analyzed using Minitab 13 and GraphPad Prism 4 computer software using the sigmoidal curve, with 5\% significance.

In vitro observation of worms treated with $P Z Q$ Mice infected with 100 cercariae derived from S. mansoni LE or LE-PZQ isolates were treated with $400 \mathrm{mg}$ / $\mathrm{kg}$ PZQ 45 days post-infection. Two hours later, mice were perfused using Roswell Park Memorial Institute medium (RPMI) 1640 medium with 2\% heparin (Smithers \& Terry 1965). Four pairs of worms originating from LE or LE-PZQ isolates were put in 6-well culture plates containing $4 \mathrm{~mL}$ RPMI 1640 supplemented with 5\% foe- tal bovine serum and $100 \mu \mathrm{g} / \mathrm{mL}$ of penicillin and streptomycin, and were cultivated in a $5 \% \mathrm{CO}_{2}$ incubator for eight days at a temperature of $37^{\circ} \mathrm{C}$. The worms derived from LE or LE-PZQ isolates and recovered from untreated mice were also cultivated and used as a control.

\section{RESULTS}

Evaluation of $P Z Q$ pressure in parasites at the intramolluscan phase - Treatment with PZQ - in this experiment, two doses of PZQ (400 or $800 \mathrm{mg} / \mathrm{kg}$ ) were tested on mice infected with LE and LE-PZQ isolates. A statistically significant difference $(\mathrm{p}<0.03)$ was observed between the mean number of worms recovered from LEPZQ (1.9) and the mean from the LE strain (0.42) when both were exposed to $400 \mathrm{mg} / \mathrm{kg}$ PZQ. Moreover, the percentage reduction of worms from the LE-PZQ (43.5\%) isolate was lower than that found for worms from the LE strain (85.6\%), suggesting that the LE-PZQ isolate showed a reduction of susceptibility to drug action. When the higher dose of $800 \mathrm{mg} / \mathrm{kg}$ was used, no significant difference could be observed between the isolates (Table I).

In the second experiment, three doses of PZQ (200, 400 or $800 \mathrm{mg} / \mathrm{kg}$ ) were used. The mean number of worms recovered from the LE-PZQ isolate treated with $200 \mathrm{mg}$ / $\mathrm{kg}$ (mean of 9.7) and treated with $400 \mathrm{mg} / \mathrm{kg}$ (mean of 5.1) was significantly lower ( $p<0.002$ and $p<0.01$, respectively) than the mean of worms recovered from the groups infected with cercariae derived from the LE strain and treated with the same doses (mean of 3.0 and 0.6, respectively). Moreover, the percentage in reduction of worms was as follows: LE-PZQ treated with $200 \mathrm{mg} / \mathrm{kg}$, $8.8 \%$, with $400 \mathrm{mg} / \mathrm{kg}, 52.3 \%$, LE treated with $200 \mathrm{mg} /$ $\mathrm{kg}, 71.7 \%$, and with $400 \mathrm{mg} / \mathrm{kg}, 94.3 \%$. No statistically significant difference between the isolates could be detected when they were submitted at the dose of $800 \mathrm{mg} / \mathrm{kg}$ (Table I), corroborating our previous results.

The mean worm reduction in experiments 1 and 2 was calculated for each PZQ dose (200, 400 or $800 \mathrm{mg} /$ $\mathrm{kg}$ ) (Fig. 1, Table II). Based on these means, the $\mathrm{ED}_{50}$ values obtained were $68 \mathrm{mg} / \mathrm{kg}$ and $362 \mathrm{mg} / \mathrm{kg}$ for the LE and LE-PZQ isolates, respectively, with these values being significantly different $(\mathrm{p}<0.01)$ (Table II). The $\mathrm{ED}_{50}$ for the LE-PZQ isolate was 5.3 times higher than that for the LE strain. These results show that there is a reduction in $S$. mansoni susceptibility to PZQ when the parasite is submitted to PZQ treatment at the intramolluscan phase.

In vitro observation of worms recovered from mice treated with $P Z Q$ - It was observed that the parasites of the LE strain derived from mice treated with $400 \mathrm{mg} / \mathrm{kg}$ PZQ were more contracted (Fig. 2A) than the parasites of LE-PZQ isolate submitted to the same PZQ dose (Fig. 2B). Additionally, more than 300 eggs were found in the cultured LE-PZQ isolate recovered from mice treated with $400 \mathrm{mg} / \mathrm{kg}$. Furthermore, eggs in all stages were observed after eight days (Fig. 2D). In contrast, the worm culture of the LE strain had a smaller number of dead eggs ( \pm 30 from total number of cultured worms) (Fig. 2C). The untreated LE and LE-PZQ isolates showed a similar number of eggs from the first stage to the mature stage (Fig. 2E, F). These results suggest that LE-PZQ isolates have reduced susceptibility to the drug. 


\section{TABLE I}

Details of two experiments performed to estimate the percentage reduction of worm burden in mice infected with Schistosoma mansoni LE strain (control) and LE-praziquantel (PZQ) and treated with PZQ

\begin{tabular}{lccc}
\hline Isolate/experiment $^{a}$ & PZQ dose $(\mathrm{mg} / \mathrm{kg})$ & Mean number of worms $\pm \mathrm{SD}$ & Worm reduction $(\%)$ \\
\hline $\mathrm{LE} / 1$ & 400,800 & $0.42 \pm 0.79,0.42 \pm 1.2$ & $85.6,85.6$ \\
$\mathrm{LE}-\mathrm{PZQ} / 1$ & 400,800 & $1.9 \pm 1.4^{b}, 0.42 \pm 0.8$ & $43.5,87.6$ \\
$\mathrm{LE} / 2$ & $200,400,800$ & $3.0 \pm 2.7,0.6 \pm 1.2,1.0 \pm 1.1$ & $71.7,94.3,90.5$ \\
$\mathrm{LE}-\mathrm{PZQ} / 2$ & $200,400,800$ & $9.7 \pm 5.8^{c}, 5.1 \pm 4.0^{d}, 1.16 \pm 1.5$ & $8.8,52.3,89.2$ \\
\hline
\end{tabular}

$a$ : mean number of worms \pm standard deviation (SD) (experiment 1: LE control: $2.92 \pm 2.93$, LE-PZQ control: $3.4 \pm 3.1$; experiment 2: LE control: $10.6 \pm 6.0$, LE-PZQ control: $10.7 \pm 6.4)$; $b$ : statistical difference between LE-PZQ $/ 1400 \mathrm{mg} / \mathrm{kg}$ and LE-PZQ $/ 1$ $400 \mathrm{mg} / \mathrm{kg}$ at $\mathrm{p}<0.01 ; c$ : statistical difference between LE-PZQ $/ 2200 \mathrm{mg} / \mathrm{kg}$ and LE-PZQ $/ 2200 \mathrm{mg} / \mathrm{kg}$ at $\mathrm{p}<0.003 ; d$ : statistical difference between LE-PZQ/2400 $\mathrm{mg} / \mathrm{kg}$ and LE-PZQ/2 $400 \mathrm{mg} / \mathrm{kg}$ at $\mathrm{p}<0.01$.

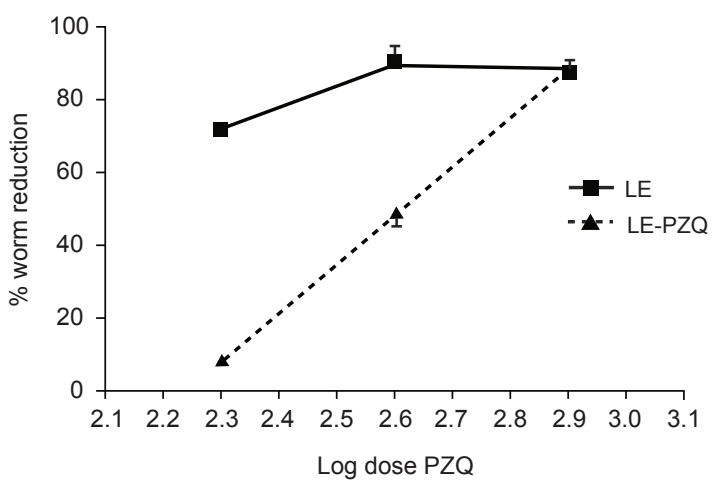

Fig. 1: computer-adjusted praziquantel (PZQ) dose-response curves for PZQ-susceptible (LE) and that isolate submitted to intramolluscan treatment with PZQ (LE-PZQ) of Schistosoma mansoni. The curves were fitted to the pooled results from two experiments on each isolate listed in Table II using GraphPad Prism 4 computer software.

\section{DISCUSSION}

According to Roos et al. (1993) and Liang et al. (2003), the process of drug pressure for selection of resistance can be carried out in the laboratory. This is important since resistant parasites may help elucidate the mechanism of the drugs.

The PZQ effective against only adult worms and another drugs effective against adult and immature $S$. mansoni worms in the vertebrate host are also effective at the intramolluscan stage of the parasite, leading to interruption of shedding of cercariae (Warren \& Weisberger 1966, Warren 1967, Coles 1979, Touassem \& Combes 1986, Coles \& Bruce 1987, Yi \& Combes 1987, Coelho et al. 1988, Riley \& Chappell 1990, Mattos et al. 2006, 2007).

Mattos et al. (2007) tested different doses and schedules of PZQ in infected B. glabrata and observed that a treatment of $1,000 \mathrm{mg} / \mathrm{kg}$ PZQ significantly interrupted almost $90 \%$ of the cercarial shedding until approximately 30 days after the end of treatment, whereas treatments with other drug formulations $(500 \mathrm{mg} / \mathrm{kg}$ PZQ and

\section{TABLE II}

Results of experiments performed to estimate the effective dose required to kill $50 \%$ of the worms $\left(\mathrm{ED}_{50}\right)$ for the susceptible Schistosoma mansoni strain (LE) and that submitted to treatments with praziquantel (PZQ) at the intramolluscan phase (LE-PZQ)

\begin{tabular}{lccc}
\hline Isolate/PZQ dose & $\begin{array}{c}\text { Mean worm } \\
\text { reduction } \\
\% \pm \mathrm{SD}\end{array}$ & $\begin{array}{c}\mathrm{ED}_{50} \\
\mathrm{mg} / \mathrm{kg}\end{array}$ & $\begin{array}{c}95 \% \\
\text { confidence } \\
\text { limits }\end{array}$ \\
\hline $\mathrm{LE} 200 \mathrm{mg} / \mathrm{kg}$ & 71.1 & 68 & - \\
$\mathrm{LE} 400 \mathrm{mg} / \mathrm{kg}$ & $89.9 \pm 6.1^{a}$ & - & $38.49-121.1$ \\
$\mathrm{LE} 800 \mathrm{mg} / \mathrm{kg}$ & $88.1 \pm 3.5^{a}$ & - & - \\
$\mathrm{LE}-\mathrm{PZQ} 200 \mathrm{mg} / \mathrm{kg}$ & 8.8 & $362^{b}$ & - \\
$\mathrm{LE}-\mathrm{PZQ} 400 \mathrm{mg} / \mathrm{kg}$ & $47.9 \pm 6.2^{a}$ & - & $125.7 / 1.044$ \\
$\mathrm{LE}-\mathrm{PZQ} 800 \mathrm{mg} / \mathrm{kg}$ & $88.4 \pm 1.3^{a}$ & - & - \\
\hline
\end{tabular}

$a$ : related to experiments 1 and $2 ; b$ : statistical difference between LE and LE-PZQ ED ${ }_{50}$. LE-PZQ ED $\mathrm{ED}_{50}$ is 5.3 times higher than $\mathrm{LE} \mathrm{ED}_{50} . \mathrm{P}<0.01 ; \mathrm{SD}$ : standard deviation.

$250 \mathrm{mg} / \mathrm{kg}$ oxamniquine in association) eliminated the parasite from the snails. Thus, the dose of $100 \mathrm{mg} /$ day/ snail used in this study represents a dose lower than that required to eliminate the parasite. Furthermore, three treatments were carried out for five consecutive days with the goal being to expose the parasite periodically to PZQ to select or induce resistance.

The results presented here demonstrate that adult worms of the LE-PZQ isolate were less susceptible to PZQ at doses of 200 and $400 \mathrm{mg} / \mathrm{kg}$ than the control strain (LE). Similar results were not observed between the LE and LE-PZQ isolates at a dose of $800 \mathrm{mg} / \mathrm{kg}$. This dose was deemed to be enough to overcome the resistance of the selected parasite. Interestingly, a dose of $800 \mathrm{mg} / \mathrm{kg}$ in the susceptible strain (LE) shows the same results as with $400 \mathrm{mg} / \mathrm{kg}$. However, when the dose is increased to $800 \mathrm{mg} / \mathrm{kg}$, the drug kills around $88 \%$ of worms in the resistant isolate (LE-PZQ). In our in vitro experiments, adult worms obtained from mice treated with PZQ from the LE-PZQ isolate were less susceptible 


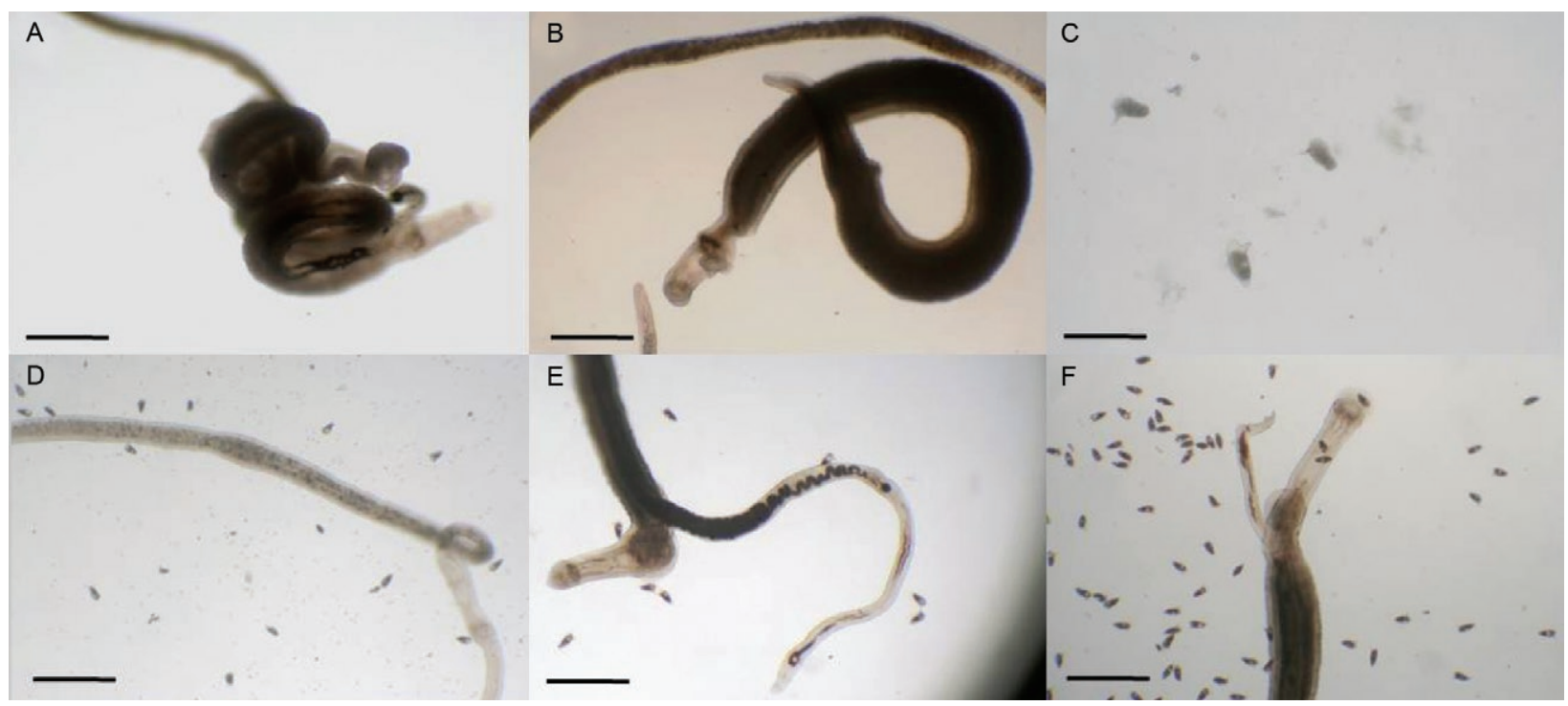

Fig. 2: adult worms of LE (susceptible) and LE-praziquantel (PZQ) (submitted to treatment with PZQ at the intramolluscan phase) derived from mice treated with $400 \mathrm{mg} / \mathrm{kg}$ PZQ and control, cultured for eight days. A: adult worm of the LE strain derived from mice treated with $400 \mathrm{mg} / \mathrm{kg}$ PZQ, exhibiting intense muscular contraction; B: adult worm of the LE-PZQ isolate derived from mice treated with $400 \mathrm{mg} / \mathrm{kg}$ PZQ, absence of muscular contraction; C: dead eggs laid by worms of the LE strain treated with $400 \mathrm{mg} / \mathrm{kg}$; D: large number of eggs in all stages laid by worms of the strain LE-PZQ treated with $400 \mathrm{mg} / \mathrm{kg}$; E: worms of the LE; F: LE-PZQ isolates derived from untreated mice (control), both have the same morphology after an eight-day-culture. Bars $=250 \mu \mathrm{m}(\mathrm{A}, \mathrm{B}, \mathrm{D}-\mathrm{F})$ and $100 \mu \mathrm{m}(\mathrm{C})$.

to the drug. The LE-PZQ isolate has been maintained in our laboratory under the pressure of PZQ. Recent results confirm that this isolate remains less susceptible to PZQ (unpublished data). The complete mechanism of action of PZQ has not been clearly defined (Doenhoff et al. 2008), but it is well known that PZQ causes a severe muscular contraction due to intense calcium influx (Pax et al. 1978), immediate tegumental lesions (Harnett \& Kusel 1986), reduction of glutathione levels (Ribeiro et al. 1998) and interruption of the excretory activity of adult worms (Kusel et al. 2006, 2007, Oliveira et al. 2006). After eight days of culture the adult worms of the LE strain showed typical alterations in morphology of susceptible parasites in contact with the drug including intense contraction, reduced oviposition and tegumental changes. Alternatively, PZQ (at $400 \mathrm{mg} / \mathrm{Kg}$ ) was not able to cause the same alterations in the motility and oviposition in the worms from the LE-PZQ isolate. The results obtained in the in vitro experiment are significant because they allow us to observe the worm condition immediately after contact with PZQ.

We found that the $\mathrm{ED}_{50}$ for the LE-PZQ isolate was significantly higher than for the LE strain in both experiments. This parameter has been used to compare susceptible and resistant worms. Cioli et al. (2004) estimated the $\mathrm{ED}_{50}$ from four susceptible and five putatively PZQresistant isolates and suggested that the value of $\mathrm{ED}_{50}$ is useful for establishing and monitoring the drug susceptibility/resistance profiles of the parasite strain. Further, they observed that the $\mathrm{ED}_{50}$ value was three times higher in the resistant isolates when compared with the susceptible ones. Our results demonstrate that the $\mathrm{ED}_{50}$ of the LE-PZQ isolate was 5.3 times higher in comparison with the $\mathrm{ED}_{50}$ for the LE strain (susceptible). Both Fallon et al. (1996) and Bennett et al. (1997) suggested that the $\mathrm{ED}_{50}$ for resistant isolates should be at least five times higher than that for those isolates susceptible to the drug. For Bennett et al. (1997), a three-to-five times higher dose is sufficient to differentiate between susceptible and resistance strains.

According to Fallon et al. (1996), induction of resistance performed in the laboratory using successive passages and treatments in mice are time-consuming and use dissimilar methodologies, thus rendering a difficult comparison of the analysis of the data.

The study by Fallon and Doenhoff (1994) aimed at selecting PZQ resistant $S$. mansoni isolates was carried out with several passages of using the entire life cycle in mice and snails, with the infected mice being submitted to treatments with increasing doses of PZQ. This model for selection of resistant $S$. mansoni lineage is complex and time-consuming, but is able to select parasites at the adult worm phase. In our experimental studies, the chemotherapeutic pressure occurs on a higher number of parasites (thousands of cercariae and sporocysts) in the snail intermediate host. Thus, the selection of resistant strains in the laboratory using $S$. mansoni at the intramolluscan phase seems to be more useful and this approach may be very important in studies concerning the development of novel antischistosomal drugs, as well as in those aimed at gaining a better understanding of the mechanisms related to resistance. These experiments must be repeated with other isolates.

In conclusion, the use of the snail as an experimental model for development of resistance in $S$. mansoni is an effective, fast, simple and cheap method. 


\section{ACKNOWLEDGEMENTS}

To Vera de Paula Ribeiro, for translating our manuscript, and to the technicians of the Mollusc Room and the Instituto de Pesquisa René Rachou-Fiocruz, for maintenance of the parasite life cycle.

\section{REFERENCES}

Abdul-Ghani RA, Loutfy N, Hassan A 2009. Experimentally promising antischistosomal drugs: a review of some drug candidates not reaching the clinical use. Parasitol Res 105: 899-906.

Bennett JL, Day T, Liang FT, Ismail M, Farghaly A 1997. The development of resistance to anthelmintics: a perspective with an emphasis on the antischistosomal drug praziquantel. Exp Parasitol 87: 260-267.

Cioli D, Botros SS, Wheatcroft-Francklow K, Mbayne A, Southgate V, Tchuenté LA, Pica-Mattoccia L, Troiani AR, El-Din SH, Sabra AN, Albin J, Engels D, Doenhoff MJ 2004. Determination of $\mathrm{ED}_{50}$ values for praziquantel in praziquantel-resistant and susceptible Schistosoma mansoni isolates. Int J Parasitol 34: 979-987.

Coelho PM, Katz N, Oliveira e Rocha M, de Souza CP, de Mello RT 1988. Schistosoma mansoni: infected snails as a tool to screen antischistosomal drugs. Int J Parasitol 18: 167-170.

Coles GC 1979. The effect of praziquantel on Schistosoma mansoni. J Helminthol 53: 31-33.

Coles GC, Bruce JI 1987. In vitro selection of drug resistant Schistosoma mansoni. Int J Parasitol 17: 767-771.

Doenhoff MJ, Cioli D, Utzinger J 2008. Praziquantel: mechanisms of action, resistance and new derivatives for schistosomiasis. Curr Opin Infect Dis 21: 659-667.

Fallon PG, Doenhoff MJ 1994. Drug-resistant schistosomiasis: resistance to praziquantel and oxamniquine induced in Schistosoma mansoni in mice is drug specific. Am J Trop Med Hyg 51: 83-88.

Fallon PG, Sturrock RF, Niang AC, Doenhoff MJ 1995. Short report: diminished susceptibility to praziquantel in a Senegal isolate of Schistosoma mansoni. Am J Trop Med Hyg 53: 61-62.

Fallon PG, Tao LF, Ismail MM, Bennett JL 1996. Schistosome resistance to praziquantel: fact or artifact? Parasitol Today 12: 316-320.

Fenwick A, Savioli L, Engels D, Robert Bergquist N, Todd MH 2003. Drugs for the control of parasitic diseases: current status and development in schistosomiasis. Trends Parasitol 19: 509-515.

Fenwick A, Webster JP 2006. Schistosomiasis: challenges for control, treatment and drug resistance. Curr Opin Infect Dis 19: 577-582.

Harnett W, Kusel JR 1986. Increased exposure of parasite antigens at the surface of adult male Schistosoma mansoni exposed to praziquantel in vitro. Parasitology 93: 401-405.

Ismail MM, Taha SA, Farghaly AM, el-Azony AS 1994. Laboratory induced resistance to praziquantel in experimental schistosomiasis. J Egypt Soc Parasitol 24: 685-695.

Kusel JR, Al-Adhami BH, Doenhoff MJ 2007. The schistosome in the mammalian host: understanding the mechanisms of adaptation. Parasitology 134: 1477-1526.

Kusel JR, Oliveira FA, Todd M, Ronketti F, Lima SF, Mattos ACA, Reis KT, Coelho PMZ, Thornhill JA, Ribeiro F 2006. The effects of drugs, ions and poly-1-lysine on the excretory system of Schistosoma mansoni. Mem Inst Oswaldo Cruz 101 (Suppl. I): 293-298.
Liang YS, Dai JR, Zhu YC, Coles GC, Doenhoff MJ 2003. Genetic analysis of praziquantel resistance in Schistosoma mansoni. Southeast Asian J Trop Med Public Health 34: 274-280.

Mattos AC, Pereira GC, Jannotti-Passos LK, Kusel JR, Coelho PM 2007. Evaluation of the effect of oxamniquine, praziquantel and a combination of both drugs on the intramolluscan phase of Schistosoma mansoni. Acta Trop 102: 84-91.

Mattos ACA, Kusel JR, Pimenta PFP, Coelho PMZ 2006. Activity of praziquantel on in vitro transformed Schistosoma mansoni sporocysts. Mem Inst Oswaldo Cruz 101 (Suppl. I): 283-287.

Oliveira FA, Kusel JR, Ribeiro F, Coelho PM 2006. Responses of the surface membrane and excretory system of Schistosoma mansoni to damage and to treatment with praziquantel and other biomolecules. Parasitology 132: 321-330.

Pax R, Bennett JL, Fetterer R 1978. A benzodiazepine derivative and praziquantel: effects on musculature of Schistosoma mansoni and Schistosoma japonicum. Naunyn Schmiedebergs Arch Pharmacol 304: 309-315.

Pellegrino J, Katz N 1968. Experimental chemotherapy of schistosomiasis mansoni. Adv Parasitol 6: 233-290.

Pellegrino J, Siqueira AF 1956. Técnica de perfusão para colheita de Schistosoma mansoni em cobaias experimentalmente infestadas. Rev Bras Malariol Doencas Trop 8: 589-597.

Ribeiro F, Coelho PM, Vieira LQ, Watson DG, Kusel JR 1998. The effect of praziquantel treatment on glutathione concentration in Schistosoma mansoni. Parasitology 116: 229-236.

Riley EM, Chappell LH 1990. Praziquantel treatment of Biomphalaria glabrata infected with Schistosoma mansoni - influence on snail fecundity. Parasitology 101: 211-217.

Roos MH, Kwa MS, Veenstra JG, Kooyman FN, Boersema JH 1993. Molecular aspects of drug resistance in parasitic helminths. Pharmacol Ther 60: 331-336.

Smithers SR, Terry RJ 1965. The infection of laboratory hosts with cercariae of Schistosoma mansoni and the recovery of the adult worms. Parasitology 55: 695-700.

Souza CP, Jannotti-Passos LK, Freitas JR 1995. Degree of host-parasite compatibility between Schistosoma mansoni and their intermediate molluscan hosts in Brazil. Mem Inst Oswaldo Cruz 90: 5-10.

Touassem R, Combes C 1986. Comparative analysis of the Schistosoma mansoni and Schistosoma bovis cercarial production under influence of praziquantel. Z Parasitenkd 72: 345-351.

Utzinger J, Keiser J 2004. Schistosomiasis and soil-transmitted helminthiasis: common drugs for treatment and control. Expert Opin Pharmacother 5: 263-285.

Warren KS 1967. Studies on the treatment of molluscan schistosomiasis mansoni with antibiotics, non-antibiotic metabolic inhibitors, molluscicides and anti-schistosomal agents. Trans $R$ Soc Trop Med Hyg 61: 368-372.

Warren KS, Weisberger AS 1966. The treatment of molluscan schistosomiasis mansoni with chloramphenicol. Am J Trop Med Hyg 15: $342-350$.

WHO - World Health Organization 2002. TDR strategic direction for research: schistosomiasis, WHO, Geneva, 6 pp.

Yi XM, Combes C 1987. Effect of praziquantel on larval stages of Schistosoma japonicum. Trans R Soc Trop Med Hyg 81: 645-650. 